\title{
Early Development of Arterial Hypertension in an Infant with Valsartan Fetopathy
}

Christina Schindera' ${ }^{1}$, Benedikt M Huber ${ }^{2}$, Mathias Nelle ${ }^{1}$, Boris Utsch ${ }^{3}$, Sybille Tschumi ${ }^{3}$ and Roland Gerull ${ }^{1 *}$

${ }^{1}$ University Hospital Inselspital Berne Childrens Hospital, Neonatology, Berne, Switzerland

${ }^{2}$ Triemli City Hospital Zurich, Pediatrics, Switzerland

${ }^{3}$ University Hospital Inselspital Berne, Childrens Hospital, Pediatric Nephrology, Berne, Switzerland

\begin{abstract}
The renin-angiotensin-aldosterone-system (RAAS) plays a pivotal role for normal kidney development. We present the case of a 34-year old second gravida who was treated with valsartan during the entire pregnancy and presented at 35 weeks of gestation with preterm labour and complete anhydramnios. After spontaneous delivery the eutrophic male infant showed typical signs of sartan fetotoxicity including neonatal anuria, enlarged hyperechogenic kidneys, initial arterial hypotension, limb contractures, skull bone hypoplasia and a narrow chest. During the first days of life arterial hypertension developed and persisted until last follow-up at 24 months. Antihypertensive therapy with amlodipine was necessary from 7 months of life until last follow-up.

Valsartan exposure especially during the second half of pregnancy causes valsartan fetotoxicity, which can lead to progressive arterial hypertension requiring antihypertensive medication. Close monitoring of patients with valsartan fetopathy is essential.
\end{abstract}

Keywords: Renal toxicity; Renal damage; Hypertension; Drug reaction; Neonatal complications

\section{Introduction}

The renin-angiotensin-aldosterone system (RAAS) is not only involved in the regulation of renal function and blood pressure but plays a pivotal role in normal kidney development [1]. Pharmacological interruption of fetal RAAS-signaling with angiotensin-converting enzyme (ACE) inhibitors or angiotensin II receptor type 1 (AT1) antagonists impairs metanephrogenesis, as well as tubular and nephrovascular development [1,2]. The wide spectrum of clinical manifestations ranges from reversible effects on amniotic fluid after drug withdrawal as well as late preterm and term gestations with only minor problems during the neonatal period to death as a result of severe complications of renal failure [3,4]. While long-term sequelae have been shown after ACE inhibitor fetopathy [5], reports of AT1 antagonist (sartan) fetotoxicity focus on the perinatal and neonatal outcome.

We present the case of a prematurely born male infant with typical signs of valsartan fetopathy and recovery of renal function during the first week of life. However, progressive arterial hypertension developed during infancy necessitating antihypertensive therapy. To our knowledge, this is the first case report on valsartan fetopathy causing prolonged arterial hypertension and requirement of antihypertensive medication in early childhood.

\section{Case Report}

5 month prior to pregnancy an otherwise healthy 34-year old woman with essential hypertension (blood pressure 160/90 $\mathrm{mmHg}$ ) was treated with valsartan $80 \mathrm{mg}$ daily. Valsartan was continued for the full length of her second pregnancy because the primary care physician was unaware of potential teratogenicity. Blood pressure was reduced to $130 / 85 \mathrm{mmHg}$. Regular sonographic examinations were normal including an ultrasound performed at 33 weeks of gestational age. At 35 weeks of gestation the woman presented with premature labour and complete anhydramnios without premature rupture of membranes. She delivered an eutrophic male infant weighing 3005 $\mathrm{g}$ (percentile 80) and measuring $52.0 \mathrm{~cm}$ (percentile 96), with a head circumference of $32.6 \mathrm{~cm}$ (percentile 30 ) and umbilical artery $\mathrm{pH}$ 7.23. Apgar score was 6 at one minute (1 for muscle tone, respiration, cyanosis and reflexes, respectively) and 9 at five and ten minutes (1 for peripheral cyanosis).

Typical signs of sartan fetotoxicity were present including neonatal anuria, arterial hypotension, limb contractures, hypocalvaria and a narrow chest. There were no signs of respiratory distress and lung hypoplasia could be excluded by chest $\mathrm{x}$-ray.

Because of complete anuria during the first day of life furosemide ( $0.34 \mathrm{mg} / \mathrm{kg}$ body weight) was administered at 22 hours of life followed by a single micturition ( $4 \mathrm{ml}$ of urine). However, anuria persisted and the boy became increasingly oedematous. After a second dose of furosemide $(2.7 \mathrm{mg} / \mathrm{kg}$ body weight $)$ at 38 hours of life in combination with a dopamine infusion ( $4 \mu \mathrm{g} / \mathrm{kg} / \mathrm{min})$ over 24 hours, diuresis finally initiated at 48 hours of life and was then within the normal range ( $>1$ $\mathrm{ml} / \mathrm{kg}$ body weight/hour) (Figure 1).

Arterial hypotension occurring in the first hour of life (mean blood pressure $25-35 \mathrm{mmHg}$ ) showed no sustained response to crystalloids and hydrocortisone. The blood pressure normalized under dopamine administration. A borderline hypertension with mean arterial pressures between 52-62 $\mathrm{mmHg}$ developed from day 8 on and persisted until discharge at day 18. Echocardiography was normal.

*Corresponding author: Roland Gerull MD, University Hospital Inselspital Berne, Pediatric Intensive Care / Neonatology, Effingerstr, 102, CH-3010 Bern, Switzerland, Tel: 0041-31- 632 0855; Fax: 0041-31-632 1405; E-mail: roland.gerull@insel.ch

Received December 19, 2011; Accepted February 22, 2012; Published February 26, 2012

Citation: Schindera C, Huber BM, Nelle M, Utsch B, Tschumi S, et al. (2012) Early Development of Arterial Hypertension in an Infant with Valsartan Fetopathy. $J$ Neonatal Bio 1:103. doi:10.4172/2167-0897.1000103

Copyright: (c) 2012 Schindera C, et al. This is an open-access article distributed under the terms of the Creative Commons Attribution License, which permits unrestricted use, distribution, and reproduction in any medium, provided the original author and source are credited. 


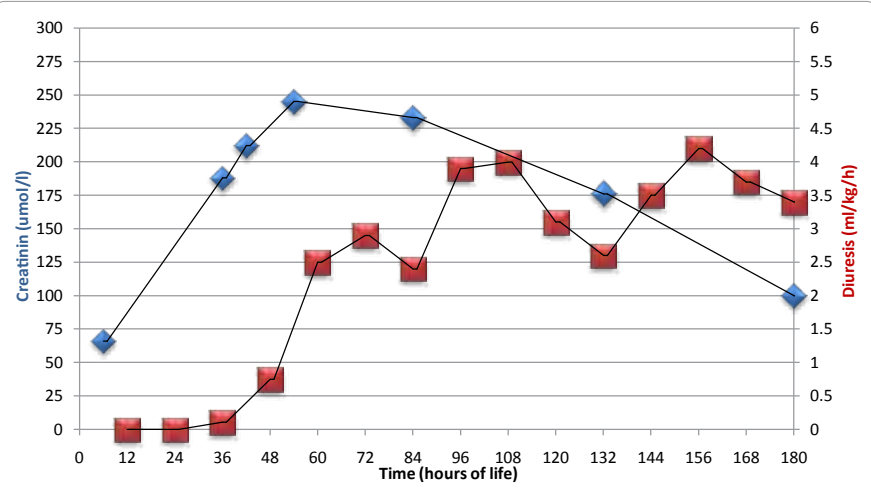

Figure 1: creatinin and diuresis during the first days of life.

Maximum serum creatinine was $245 \mu \mathrm{mol} / \mathrm{l}(2.8 \mathrm{mg} / \mathrm{dl})$ on day 3 and decreased to normal age-related values within 14 days (Figure 1). There was no electrolyte or acid-base imbalance. Urine analysis showed glucosuria and urine protein analysis on the $10^{\text {th }}$ day of life revealed a combined selective glomerular and complete tubulointerstitial proteinuria. Ultrasound examinations showed bilaterally enlarged kidneys with a hyperechogenic cortex.

On regular follow-up visits during the first 24 months of life, physical examination and neurological development were normal. However, arterial hypertension persisted with $122 / 89$ $\mathrm{mmHg}$ (percentile 95: 102/55 $\mathrm{mmHg}$ ) [6], requiring the start of an antihypertensive therapy with amlodipine at 7 months of age. Initial dosage was $0.2 \mathrm{mg} / \mathrm{kg}$ body weight daily, which was increased to $0.4 \mathrm{mg} / \mathrm{kg}$ body weight daily due to a borderline blood pressure of $102 / 68 \mathrm{mmHg}$ (percentile 95: $106 / 59 \mathrm{mmHg}$ ) at 15 months of life and $111 / 60 \mathrm{mmHg}$ (percentile $95: 106 / 59 \mathrm{mmHg}$ ) at 17 months of life [6]. Serum levels of creatinine and urea nitrogen were within the normal range. Urinalysis showed mild renal albumin loss $(2.6 \mathrm{~g} / \mathrm{mol}$ creatinine) up to 12 months of life, which subsequently normalized. Although renal size had normalized by three months of life, the morphologic changes in renal sonography (hyperechogenic renal parenchyma and a diminished corticomedullary differentiation) persisted during controls for now 24 months.

\section{Discussion}

Renal development depends on normal RAAS-function and disorders either due to mutations in RAAS-genes or due to pharmacological inhibition of RAAS-components result in renal tubular dysgenesis. This severe developmental disorder is associated with significant fetal and neonatal morbidity and mortality [2-4] as well as long-term sequelae for renal function and blood pressure [5]. Fetal AT1 and angiotensin II receptor type 2 (AT2) receptors are localized to renal differentiating structures in a temporally and spatially specific pattern. AT2 receptors are more predominant in the undifferentiated renal tissue during the first half of pregnancy, while AT1 receptors are expressed in more differentiated tissue in the second half of pregnancy, responsible for final differentiation of nephrovascular architecture. Selective blockage of AT1 receptors during second half of pregnancy is therefore associated with severe tubular dysgenesis and renal impairment. Accordingly, our patient probably developed renal hypoperfusion due to arterial hypotension in-utero and consecutive anhydramnios in late pregnancy. In contrast, fetal complications are less frequently observed with maternal AT1 receptor antagonist treatment during first half of pregnancy $[4,7,8]$, where AT1 receptors seem to play a minor role [9]. When AT1 receptor antagonist treatment is withdrawn during early pregnancy, the fetotoxic effect of anhydramnios may be reversible [7].

In the so far largest case series, Alwan et al. [3,4] reviewed 20 cases of fetal second and third trimester exposure to AT1 receptor antagonists. Twenty-five percent of the pregnancies were prematurely interrupted because of stillbirth or termination, $27 \%$ of the remaining 15 live births died within 4 days. Regarding fetal and neonatal renal functioning, $90 \%$ had oligohydramnios, $53 \%$ of live births developed anuria after birth and $55 \%$ of the fetuses showed enlarged kidneys. However no long-term follow-up on the surviving neonates was conducted in this study; therefore further development of renal function remains unclear.

In the presented case, an initially favourable course of renal function was observed, with normal diuresis following repetitive pharmacological stimulation within the first days of life and serum creatinine normalized within two weeks of life and remained within normal range until the last follow-up at 24 months of life. However, renal structural alterations persisted and arterial hypertension developed during infancy necessitating the start of an antihypertensive treatment at seven months of age. In parallel renal sonography reported hyperechogenic renal parenchyma and diminished corticomedullary differentiation until 16 months of life. These complications are known from children with fetal exposure to ACE inhibitors; in those children arterial hypertension first occured between three and ten years of age [5]. The course of arterial hypertension and morphological changes remain unclear making close follow-up necessary.

In summary, valsartan exposure during second half of pregnancy causes fetotoxicity with neonatal acute anuric renal failure. After initial recovery of renal functioning, progressive arterial hypertension may develop necessitating antihypertensive medication. Therefore, close follow-up of children with valsartan fetopathy is essential.

\section{References}

1. Chen $Y$, Lasaitiene D, Friberg $P(2004)$ The renin-angiotensin system in kidney development. Acta Physiol Scand 181: 529-535.

2. Quan A (2006) Fetopathy associated with exposure to angiotensin converting enzyme inhibitors and angiotensin receptor antagonists. Early Hum Dev 82: 23-28.

3. Alwan S, Polifka JE, Friedman JM (2005) Angiotensin II receptor antagonist treatment during pregnancy. Birth Defects Res A Clin Mol Teratol 73: 123130

4. Alwan S, Polifka JE, Friedman JM (2005) Addendum: sartan treatment during pregnancy. Birth Defects Res A Clin Mol Teratol 73: 904-905.

5. Laube GF, Kemper MJ, Schubiger G, Neuhaus TJ (2007) Angiotensinconverting enzyme inhibitor fetopathy: long-term outcome. Arch Dis Child Fetal Neonatal Ed 92: F402-403.

6. (1996) Update on the 1987 Task Force Report on High Blood Pressure in Children and Adolescents: a working group report from the National High Blood Pressure Education Program. National High Blood Pressure Education Program Working Group on Hypertension Control in Children and Adolescents. Pediatrics 98: 649-658.

7. Berkane N, Carlier P, Verstraete L, Mathieu E, Heim N, et al. (2004) Feta toxicity of valsartan and possible reversible adverse side effects. Birth Defects Res A Clin Mol Teratol 70: 547-549.

8. Serreau R, Luton D, Macher MA, Delezoide AL, Garel C, et al. (2005) Developmental toxicity of the angiotensin II type 1 receptor antagonists during human pregnancy: a report of 10 cases. BJOG 112: 710-712.

9. Norwood VF, Craig MR, Harris JM, Gomez RA (1997) Differential expression of angiotensin II receptors during early renal morphogenesis. Am J Physiol 272: R662-668. 